\title{
Design and Key Technology of Extra-high Voltage Power Transmission and Management System for SPS
}

\author{
WANG Pengpeng Hou Xinbin \\ Institute of Manned Space System Engineering, China Academy of Space Technology, Beijing, \\ China
} 23593585@qq.com

Key words: SPS, power transmission \& control system, Extra-high voltage (EHV)

Abstract: According to the difference between platform's and play loads' put-in voltage, a design of power transmission and management system for SPS is proposed, in which high and low voltages hybrid power supply technology is applied. The electrical power from SPS to the earth can be transmitted efficiently, and the operating stability of SPS can be insured. Considering the extra-high voltage of SPS, which is six orders of magnitude higher than the others satellites, the research and manufacture feasibility of high-voltage solar cell array, high-voltage cable high-voltage power transformer and high-voltage relay are analyzed, and key research direction are mentioned. After comparing different space plasma environment protecting technologies, a conclusion that the initiative protecting technology is feasible for SPS can be obtained..

\section{Introduction}

Solar Power Satellite (SPS) is the strategic combination of new energy and space, it converts solar energy into electrical energy in the space, and then through the wireless transmission way to transmit power to the ground, after conversion clean electricity can be sent into the ground's grid ${ }^{[1]}$. SPS can make full use of the advantages of the solar energy, such as vast amounts of energy and continuous power supply, to meet the high requirement for clean energy, at the same time it will promote the sustainable development in the field of clear energy and space technology.

At present, the concept of SPS receives extensive attention of the world, which represented by the United States and Japan, both of them aim at realizing commercial operation in the year 2030. The United States plans to realize the $10 \mathrm{MW}$ testing system in space in 2020, and Japan proclaims technology roadmap of achieving $1 \mathrm{GW}$ commercial operation in 2030. In addition, the European space agency (ESA) set up the European SPS research team in August 2002 $2^{[2]}$, our country also has established a dedicated team to do advance research about SPS ${ }^{[3]}$. Usually SPS's power capacity is in gigwatts class $\left(10^{9} \mathrm{~W}\right)$, six times higher than the current satellite, so SPS needs special power transmission and management technology.

At present, researchers always focus on advanced technology such as the multilayer efficient solar cells, thin film solar cells, microwave converter with high efficiency, light space structure, but the research on power management technology is rare. The only available report is SPS-1979 which is designed by the United States in 1979, which put forward the detailed design of the power management system. In this system, control equipments for SPS, such as attitude control, thermal control, power management, plant maintenance and so on, are powered by the power control module, whose input voltage is $40 \mathrm{kV}$, but these control equipments operate with just $100 \mathrm{~V}$ voltage supply, the power supply voltage of microwave tube heater is even only $10 \mathrm{~V}$. So it puts forward a 
high demand for the performance of high to low voltage converters, or through multistage converter, obviously it will lower the efficiency of the whole system. Therefore, using high voltage to be platform equipment power supply should be avoided in design, they should use low voltage power system directly. According to the different demand, high and low voltage power transmission and management system is designed.

\section{power transmission and management system}

In SPS, the platform control equipment (attitude control, thermal control, power management, plant maintenance, etc.) need lower voltage and lower power, and payload of SPS, microwave tube need ultra-high voltage up to $\mathrm{kV}$ class. So energy from the solar cell array can be divided into two parts, divided into two kinds of voltage class independently, $\mathrm{kV}$ high voltage and $100 \mathrm{~V}$ low voltage. According to the design idea, the high and low voltage power transmission and management system is designed, which is shown in Fig. 2.

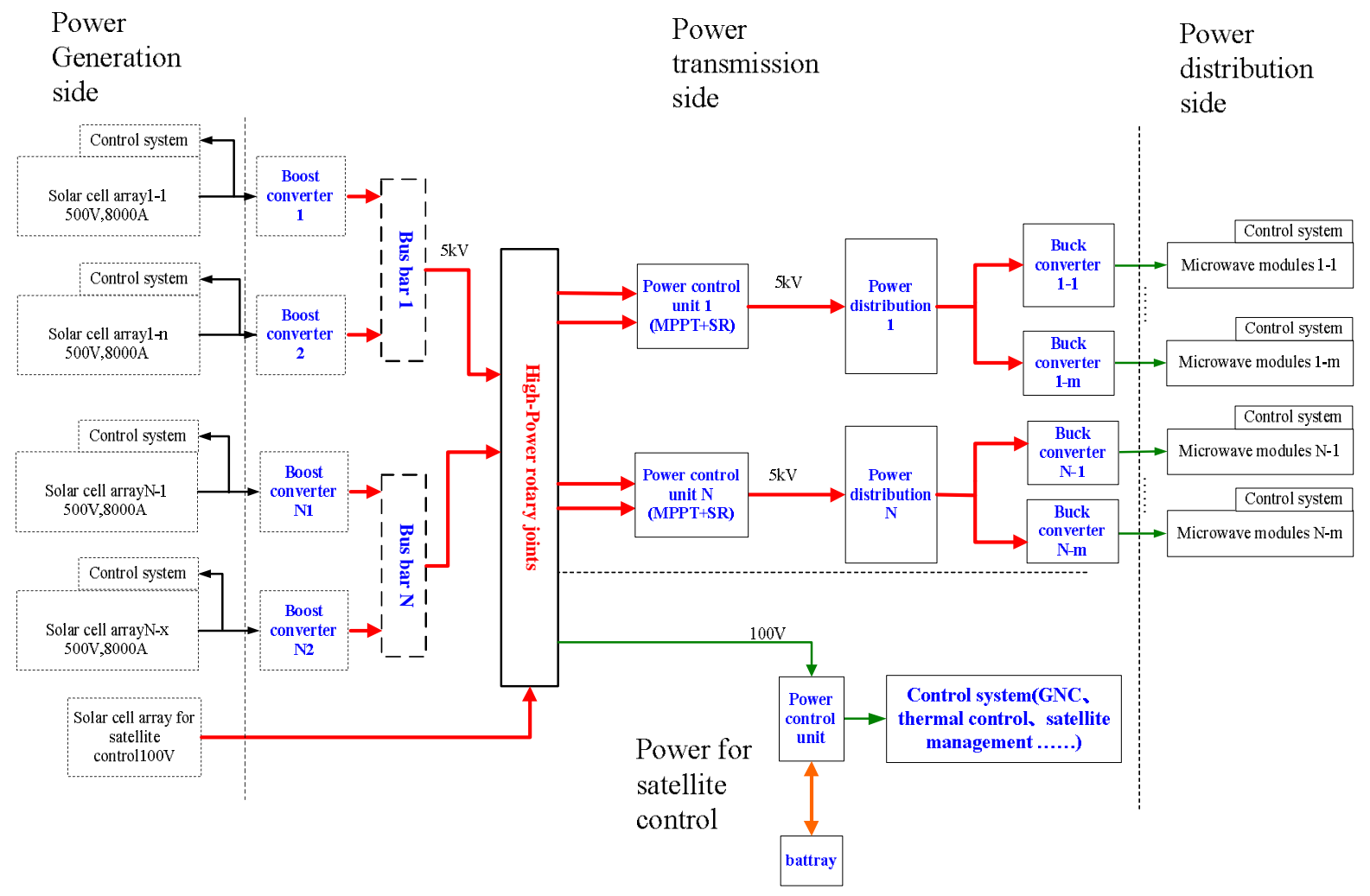

Fig. 2 Configuration of power transmission \& management system of SPS

In figure 2 , low voltage bus of $100 \mathrm{~V}$ supply power to control system, and low voltage bus is independent of high voltage power supply system for the microwave tube. In addition, according to the predetermined orbit, there is short-term shadow, in order to ensure the continued operation of SPS, we must design a complete set of solar cell array-battery power supply system, which include solar cell arrays supply power in illumination area, batteries supply power in shadow area and power regulation device (PCU) which is used to maintain voltage stability. With rational design series-parallel number of solar cell arrays and batteries, and using the PCU to make the system output voltage stability in about $100 \mathrm{~V}$, to maintain stable operating of SPS .

At present, high power microwave tube which is designed for China's SPS need the input voltage of $5 \mathrm{kV}$. Microwave tube is the payload of SPS, whose function is converting electrical energy from the solar cell to microwave and transmitting to the receiving device on ground. In the shadow area, the solar cell arrays can't generate power, except these control equipments, microwave tube don't 
need power supply (microwave tube control system is support by low voltage bus), so the high voltage bus only need solar cell arrays, no batteries. In order to improve the sun cell arrays' power, set the power controller, with maximum power point tracking (MPPT) control mode ${ }^{[5]}$. When the solar cell arrays' output power is more than the transmission capacity of microwave tube, the excess energy will be consumed by shunt regulator (SR). In order to improve the reliability of the system, multiple high voltage buses are set up, and they are all isolated, can work individually or standby for each other, which means if a single bus or more fail, it will not affects other buses.

\section{key Technology analysis}

In SPS, as a result of $5 \mathrm{kV} E H V$, it has put forward higher demands for the solar cell array, space plasma shielding, high voltage protection, etc.

\section{high voltage solar cell array}

The solar cell array is the input end of power transmission system, the characteristics of high voltage solar cell array will decide the design of power transmission and management system directly. In order to realize the EHV power supply, in the 1970s, the United States has carried out a lot of research in this field. Aim at the need of the high voltage propulsion system, Boeing, Hughes and some other companies have carried out design and research of $16 \mathrm{kV}$ high-voltage solar cell array. As research continues, because of the solar cell array's discharge problems caused by space plasma environment, related research has not pushed down substantively. In 2012, Japan developed a mall testing satellite HORYU-II, launched in May 2012, and operated on the sun synchronous orbit at the height of $680 \mathrm{~km}$. The satellite's main task is to validate the $300 \mathrm{~V}$ high voltage solar cell array technology. The solar cell is three junction $\mathrm{GaAs}$ cell $(\mathrm{GaAs} / \mathrm{InGaP} / \mathrm{Ge})$, and multiple sets of cells were connected in series to form high voltage. The solar cells' surfaces were covered by ethylene-tetra-fluoro-ethylene (ETFE) and semi-conducting coating to reduce the risk of discharge. Ground test shows $800 \mathrm{~V}$ voltage difference won't cause discharge, and on-orbit test indicates that the solar cell arrays' working voltage is up to $350 \mathrm{~V}$, which is the highest voltage of the solar cell array on orbit currently.

Squarerigger high-power solar cell array designed by ABEL company in the United States adopted the ENTECH company's concentrator solar cell array. The design of Squarerigger high-power solar cell arrays' power will be $100 \mathrm{~kW}$ to $\mathrm{MW}$ level, and working voltage is up to 1000V. The Fresnel lens is adopted as the concentrating system of the concentrator solar cells. Because of the concentrating system, the spacing between solar cells is bigger to reduce the risk of discharge and improve the working voltage of the solar cell array.

\section{space plasma shielding}

Orbit of SPS is geosynchronous orbit, whose plasma environment is very complex, so the solar cell arrays are prone to high potential of electrostatic discharge induced by different amounts charged. Though without enough energy, electrostatic discharge can't destroy solar cell arrays, but the secondary discharge caused by electrostatic discharge can cause permanent short circuit damage to high voltage solar cell array ${ }^{[6]}$. Therefore, for high-voltage photovoltaic (pv) system in space, how to prevent the secondary discharge of solar cell array caused by space plasma environment, is the key technology to ensure high reliability operation of solar cell array.

At present, the plasma shielding method is roughly divided into two types of passive and active. The main mean of passive shielding is strengthening the insulation to inhibit electrostatic discharge, and improve the threshold voltage of secondary discharge. But using passive protection has certain limitations, did not completely solve the problem of electrostatic accumulation, when the voltage up to a certain degree, it still can cause discharge. Active protection method has been applied in the 
international space station (ISS). Plasma contactor emits electronic to make spacecraft and the surrounding environment are equipotential to eliminate surface charging of solar cell array ${ }^{\text {[7] }}$, which solve electrostatic discharge problem from the source by controlling the accumulation of static-electricity. The plasma shielding methods of our country's existing in-orbit spacecraft are mostly passive, but the active plasma shielding technology of ISS is more suitable for SPS such a Extra-high voltage large spacecraft.

\section{high voltage protection}

For high voltage protection, key parts of power distribution and transmission are cable network, power conversion, relay, etc.

At present, a small amount of space products use $\mathrm{kV}$ cable, which is the highest voltage level in space, but SPS's voltage is higher, so insulation layer of cable is thicker, and resulting problems are heavy quality, poor cooling capacity, large turning radius. These are all need to do further research, to solve through optimization materials and structure design of insulation layer.

Developing the power conversion technology of high voltage, high efficiency, lightweight and high power density is the basis of space high voltage power transmission and management. It needs to carry out research from power conversion topology structure, new materials and devices, optimization control and so on. It is needed to put forward power conversion topologies structure suitable for space requirements, and develop multilevel power conversion, using multiple series of low-voltage power unit combine into high voltage high power conversion. Second, at the device level, it is needed to apply a new generation of wide band gap power devices, improve performance of single device, and develop combination technology, to ensure that the device or device combination module has enough energy transformation ability. At last, it is need to research the upper system control and the underlying power pulse control for converter, to ensure the optimization control of the energy flow, and study the transient energy transformation rule of power electronic transformation, to improve the reliability, the efficiency and electromagnetic compatibility of converter.

For relay, current space products use up to $100 \mathrm{~V}$ level, the vacuum relay used in 1979-SPS is $\mathrm{kV}$ level. In addition to the vacuum relay, in theory, hybrid relay (EMPC) also can be used in kV level. Hybrid relay is composed of mechanical contact and solid-state power transistor connected in parallel ${ }^{[8]}$, whose voltage with-stand level depends on the level of solid-state power transistor. High voltage high-power solid-state power transistor has been widely used in civilian areas, with rated voltage up to $6.5 \mathrm{kV}$, which can meet the needs of SPS. This mature technology can be used to design hybrid relay suitable for space environment.

\section{Conclusions}

Faced the task of developing SPS, the design of 1979-SPS power management system is analyzed, found it adopts high voltage after reduction voltage to supply power to low voltage equipment, this method lower the efficiency of the system. Therefore, considering of the different voltage demand between power station control equipment and payloads, the mixed high and low voltage power transmission and management system is put forward, and design the system framework. Because of ultra-high voltage, these key technologies, such as solar cell array, plasma shielding, high voltage protection are more important and difficult. After analysis these conclusions are put forward: active plasma shielding technique is more suitable for SPS EHV system; The focus of high voltage cable follow-up research are reducing quality and solving the problem of cooling capacity; Through multiple series combination of low voltage power units to realize high voltage high power electric conversion; Using high voltage solid-state power transistor as subsequent high voltage relay 
research direction. The above analysis results can be technical references to further research of SPS.

\section{References}

[1] Zhuang Fenggan. Strategic combination of astronautics and new energy - solar power satellite[J]. Aerospace China, 2008(7): 36-39 (in Chinese)

[2] Hou Xinbin, Wang Li, Zhu Yaoping, et al. Summary of the international space solar power systems[J]. Acta Energiae Solaris Sinica, 2009, 30(10): 1443-1448 (in Chinese)

[3] Fan Bin, Zi Xiao. Chinese scientists propose roadmap for space solar power station (part 2) [J]. Aerospace China, 2011(1): 28-30 (in Chinese)

[4] G R Woodcock. Solar power satellite system definition study[Z]//Volume III, Phase I, Final report: Reference System Description D180-25037-3. Washington D.C.: NASA, 1979: 12-76

[5] Liu Zhigang, Cai Xiaodong, Chen Qi, et al. Overview of space power system design using MPPT for deep space spacecraft [J]. Spacecraft Engineering, 2011, 20(5): 105-110 (in Chinese)

[6] Yang Chuibai, Liang Jinbao, Wang Shijin. Monitoring method for solar PV array ESD of GEO spacecraft [J]. Acta Energiae Solaris Sinica, 2008, 29(2): 135-138 (in Chinese)

[7] Steve Koontz, Mark Valentine, Thomas Keeping, et al. Assessment and control of spacecraft charging risks on the International Space Station, NASA 20040111075[R].Washington D.C.: NASA, 2004

[8] Yang Shanshui, Wang Li, Ma Shuangwei. Research on the technology of electro-mechanical power controller with a novel structure[J]. Acta Aeronautica et Astronautica Sinica, 2007, 28(5): 1195-1199 (in Chinese) 